\title{
Hemodynamic Responses during Insertion of Laryngeal Mask Airway versus Conventional Intubation
}

\author{
VIJAI KUMAR ${ }^{1}$, MUHAMMAD FAISAL FAROOQ ${ }^{2}$, SHAKIL MALIK ${ }^{3}$, ZAMIR AHMED ${ }^{4}$, MUHAMMAD NADEEM MUNEER ${ }^{5}$ \\ ${ }^{1-4}$ Consultant Anaesthesiologists, Department of Anaesthesia, Sindh Institute of Urology and Transplantation Karachi \\ ${ }^{5}$ Associate Professor, Department of Anaesthesia, Jinnah Postgraduate Medical Centre, Karachi \\ Correspondence to Dr. Vijai Kumar, E-mail: drvijayvalecha@outlook.comCell 0333-7308228
}

\begin{abstract}
Aim: To determine the hemodynamic response during insertion of laryngeal mask airway versus conventional intubation.

Study design: Randomized controlled trial.

Place and duration of study: Department of Anaesthesia, Jinnah Postgraduate Medical Centre, Karachi from $9^{\text {th }}$ June 2016 to $10^{\text {th }}$ December 2016.

Methodology: One hundred and fifty-eight patients were enrolled, and they were divided in two groups; Group A (laryngeal mask airway) and patients falling in group B (conventional method). Baseline haemodynamic parameters were noted, and all patients were induced with propofol $2 \mathrm{mg} . \mathrm{kg} 1$. In group B, succinylcholine $1.5 \mathrm{mg} . \mathrm{kg}-1$ was used to facilitate intubation. After induction appropriate size endotracheal tube or laryngeal mask airway were inserted for airway control. For first five minutes after intervention, analgesics and any other stimulation were avoided, in order to prevent any haemodynamic alteration. All airway interventions were done by anaesthesiologist who had more than 5 years post fellowship experience. Mean arterial pressures were recorded. Initial haemodynamic parameters were measured when the patient enter the operating room and then second reading taken just after induction of anaesthesia, third reading recorded one minute and fourth reading 5 minutes after the intervention (i.e., after passing either endotracheal tube or laryngeal mask airway).

Results: The average mean arterial pressure during process of intubation of patients in Group laryngeal mask airway group was $105.21 \pm 5.90$ while in conventional group the average mean arterial pressure was $102.21 \pm 4.29$ with $P$-value $=0.001$.

Conclusion: Intubation through intubating laryngeal mask airway is accompanied by minimal cardiovascular responses than those associated with direct laryngoscopic tracheal intubation, so it can be used for patients in whom a marked pressor response would be deleterious.

Keywords: Intubating laryngeal mask airway, Conventional laryngoscopy, Hemodynamic responses, Airway morbidity,
\end{abstract}

\section{INTRODUCTION}

Adequate airway management is an essential skill for anaesthetists. Airway can be maintained by various ways in which endotracheal intubation is the gold standard. Use of laryngoscopy and intubation causes rise in blood pressure and pulse rate, cardiovascular response to laryngoscopy and tracheal intubation have been well documented, and a number of methods have been used to attenuate them. ${ }^{1}$ This response is hazardous in patients with compromised cardiovascular system especially if this response is left unchecked. $^{2}$ In two different studies which compared hemodynamic responses to three different intubating devices showed that laryngoscopic intubation has the greater response as compared with laryngeal mask airway especially in hypertensive patients ${ }^{3,4}$. There are many pharmacological agents which attenuates this response like nitrous oxide, ${ }^{5}$ propofol $^{6}$, remifentanil and alfentanil, ${ }^{7}$ esmolol and nicardipine, ${ }^{2}$ labetalol, ${ }^{8}$ clonidine and gabapentin etc ${ }^{9}$.

Laryngoscopy and intubation stimulate neural pathway in pharynx leading to hypertension and tachycardia. This hemodynamic stress response to tracheal intubation can precipitate adverse cardiovascular events in

Received on 19-12-2020

Accepted on 20-04-4041 patients with and without cardiovascular disease. Hypertensive patient's show exaggerated response to laryngoscopy and intubation ${ }^{3}$. The major cause of this sympathoadrenal response to tracheal intubation arises from stimulation of the supraglottic region by tissue irritation induced by direct laryngoscopy ${ }^{4}$. In a study mean arterial pressure (MAP) was $104.43 \pm 5.90$ and $102.15 \pm 4.16$ in laryngeal mask airway group and conventional group respectively ${ }^{10}$.

The present study is designed to compare hemodynamic response between insertion of laryngeal mask airway verses conventional intubation and most efficient of the two were adopted in future. The utilization of the study is to avoid untoward effects of different technique used for intubation. This will cut down the financial burden on the patient and will reduce the bed occupancy of the institute.

\section{MATERIALS AND METHODS}

This randomized controlled trial study was conducted at Department of Anaesthesia, Jinnah Postgraduate Medical Centre, Karachi from $9^{\text {th }}$ June 2016 to $10^{\text {th }}$ December 2016. One hundred and fifty-eight patients were enrolled, and they were divided in two groups; Group A intubated by laryngeal mask airway and patients falling in group $B$ intubated by conventional method. All patients age 25 to 50 
years, ether gender, ASA physical status I and II, Mallampati I and II and undergoing elective general surgeries like hernia repair, cholecystectomy, etc under general anaesthesia were included. Patients having cardiac conduction defects confirmed on ECG, history of epilepsy on treatment confirmed on physician's prescription, use of antiarrhythmic medications confirmed on physician's prescription and IHD and HTN confirmed on medical documents were excluded.

On arrival in the operating room, IV line was maintained with $20 \mathrm{G}$ cannula and lactated ringer solution was started. Patients were monitored with automated noninvasive blood pressure, electrocardiograph, pulse oximeter and end tidal CO2. Baseline haemodynamic parameters were noted, and all patients were induced with propofol 2mg.kg 1. In group B, succinylcholine 1.5mg.kg-1 was used to facilitate intubation. After induction appropriate size ETT or LMA were inserted for airway control. For first five minutes after intervention, analgesics and any other stimulation were avoided, in order to prevent any haemodynamic alteration. All airway interventions were done by anaesthesiologist who had more than 5 years post fellowship experience. Appropriate placement of both devices was confirmed by capnograph, and bilateral chest auscultation was also done in group B. Mean arterial pressures were recorded. Initial haemodynamic parameters were measured when the patient enter the operating room and then second reading taken just after induction of anaesthesia, third reading recorded one minute and fourth reading 5 minutes after the intervention (i.e., after passing either ETT or LMA). Mean of all these reading was calculated and recorded along with baseline demographics like age, gender, height, weight and BMI. The data was entered and analyzed through SPSS-20. The two groups were compared in terms of MAP, ' $t$ ' test and Chi square test were applied and $\mathrm{P}$ value $\leq 0.05$ were considered as significant.

\section{RESULTS}

There were $110(52.38 \%)$ male patients in which 52 $(65.82 \%)$ were in group A while the rest of $58(73.41 \%)$ male were in group B. There were only $48(30.38 \%)$ female patients in this study, in which $27(34.18 \%)$ were in group $A$ and $21(26.58 \%)$ were in group $B$. The male to female ratio was higher. The ASA status there were 83(52.53\%) patients with ASA I status in which $32(40.51 \%)$ were in group A while the rest of $51(78.65 \%)$ patients with ASA II were in group B. There were $75(47.47 \%)$ patients with ASA status II in this study, in which $47(59.49 \%)$ were in group A and $28(35.44 \%)$ were in group $B$. The Mallampati status there were $83(52.53 \%)$ patients with I status in which $40(50.63 \%)$ were in group A while the rest of $43(54.43 \%)$ patients with II status were in group B. There were $75(47.47 \%)$ patients with mallampati status II in this study, in which $39(49.37 \%)$ were in group A and 36(45.57\%) were in group B. The obesity there were $40(25.32 \%)$ patients were obese in which $21(26.58 \%)$ were in group $A$ while the rest of $19(24.05 \%)$ patients were obese in group $B$. There were $118(74.68 \%)$ patients were non-obese in this study, in which $58(73.42 \%)$ were in group $A$ and $60(75.95 \%)$ were in group B (Table 1).
The average age of patients in Group A was $36.54 \pm 9.45$ years while in Group B the average age was $35.78 \pm 11.89$ years. Overall average age of patients was $37.45 \pm 11.50$ years. The average BMl of patients in Group A was $23.58 \pm 2.45 \mathrm{~kg} / \mathrm{m}^{2}$ while in Group B the average BMI was $24.65 \pm 1.56 \mathrm{~kg} / \mathrm{m}^{2}$. Overall average BMl of patients was $23.21 \pm 2.30 \mathrm{~kg} / \mathrm{m}^{2}$. The average Mat at baseline of patients in Group A was $91.65 \pm 3.21$ while in Group B the average MAP was $92.75 \pm 2.98$. Overall average MAP of patients was $91.53 \pm 2.34$. The average MAP during process of intubation of patients in Group A was 105.21 \pm 5.90 while in Group B the average MAP was $102.21 \pm 4.29$ with Pvalue $=0$. 001.we found significant difference in hemodynamic response in both groups. Overall average MAP of patients was $104.78 \pm 5.41$ (Table 2).

Stratification for hemodynamic response (MAP) was stated with respect to age, ASA status, Mallampati, obesity and gender. $P$-values were significant with $p$-value $<0.05$. All stratified groups showed significant difference of MAP between both groups (Table 3 ).

Table 1: Demographic information of the patients

\begin{tabular}{|c|c|c|}
\hline Variable & $\begin{array}{l}\text { Laryngeal mask } \\
\text { airway group }\end{array}$ & $\begin{array}{c}\text { Conventional } \\
\text { group }\end{array}$ \\
\hline \multicolumn{3}{|l|}{ Gender } \\
\hline Male & $52(65.82 \%)$ & $58(73.41 \%)$ \\
\hline Female & $27(34.18 \%)$ & $21(26.58 \%)$ \\
\hline \multicolumn{3}{|l|}{ ASA status } \\
\hline 1 & $32(40.51 \%)$ & $51(78.65 \%)$ \\
\hline II & $47(59.49 \%)$ & $28(35.44 \%)$ \\
\hline \multicolumn{3}{|c|}{ Mallampati status } \\
\hline I & $40(50.63 \%)$ & $43(54.43 \%)$ \\
\hline II & $39(49.37 \%)$ & $36(45.57 \%)$ \\
\hline \multicolumn{3}{|l|}{ Obesity } \\
\hline Yes & $21(26.58 \%)$ & $19(24.05 \%)$ \\
\hline No & $58(73.42 \%)$ & $60(75.95 \%)$ \\
\hline
\end{tabular}

Table 2: Descriptive statistics of variables

\begin{tabular}{|l|c|c|}
\hline \multicolumn{1}{|c|}{ Variable } & $\begin{array}{c}\text { Laryngeal mask } \\
\text { airway group }\end{array}$ & $\begin{array}{c}\text { Conventional } \\
\text { group }\end{array}$ \\
\hline Age (years) & $36.54 \pm 9.45$ & $35.78 \pm 11.89$ \\
\hline BMI & $23.58 \pm 2.45$ & $24.65 \pm 1.56$ \\
\hline MAP(Baseline) & $91.65 \pm 3.21$ & $92.75 \pm 2.98$ \\
\hline MAP & $105.21 \pm 5.90$ & $102.21 \pm 4.29$ \\
\hline P value & \multicolumn{2}{|c|}{0.001} \\
\hline
\end{tabular}

Table 3: Stratification for hemodynamic response (MAP) in both groups with respect to effect modifiers

\begin{tabular}{|c|c|c|c|}
\hline Variable & $\begin{array}{l}\text { Laryngeal mask } \\
\text { airway group }\end{array}$ & $\begin{array}{l}\text { Conventional } \\
\text { group }\end{array}$ & $P$ value \\
\hline \multicolumn{4}{|l|}{ Gender } \\
\hline Male & 52 & 58 & 0.001 \\
\hline Female & 27 & 21 & 0.001 \\
\hline \multicolumn{4}{|c|}{ ASA status } \\
\hline I & 32 & 51 & 0.001 \\
\hline II & 47 & 28 & 0.001 \\
\hline \multicolumn{4}{|c|}{ Mallampati status } \\
\hline I & 40 & 43 & 0.001 \\
\hline II & 39 & 36 & 0.001 \\
\hline \multicolumn{4}{|l|}{ Obesity } \\
\hline Yes & 21 & 19 & 0.001 \\
\hline No & 58 & 60 & 0.001 \\
\hline \multicolumn{4}{|c|}{ Age (years) } \\
\hline$<35$ & $105.08 \pm 5.90$ & $102.68 \pm 4.57$ & 0.001 \\
\hline$>35$ & $105.68 \pm 5.22$ & $102.31 \pm 5.03$ & 0.001 \\
\hline
\end{tabular}




\section{DISCUSSION}

Patients in both groups were similar in terms of demographic characteristics such as age, height, weight, and gender. Moreover, all patients were similar in terms of Mallampati scores, where the findings were consistent with those of previous studies ${ }^{11-14}$. The main results demonstrated that hemodynamic variables after insertion of laryngeal mask airway and combitube airway devices were almost always significantly different from the first group. In fact, hemodynamic variables in groups 2 and 3 showed significant increase in diastolic blood pressure as compared to the control group (mask ventilation) at all times after insertion. However, the most significant difference was observed between groups 2 and 3 in the first minute after insertion. Moreover, the values of systolic, diastolic pressures and heart rates in combitube group higher than in laryngeal mask airway group. Although the heart rate in one minute after airway manipulation showed no significant difference between groups 1 and 2, this parameter revealed a significant increase. These results were consistent with those obtained by Cook et $\mathrm{al}^{15}$, particularly in terms of changes in systolic and diastolic blood pressures. As for heart rate 3 minutes after insertion, however, they were inconsistent with the results of the current study, where heart rate in group 3 was significantly higher than group 1 , while Cook et $\mathrm{al}^{15}$ did not report so. Such inconsistency might have been due to different age of patients involved in the two studies as well as difference in ASA. In the current study, patients with any underlying diseases were excluded. Furthermore at 5 minutes after insertion, the systolic blood pressures and heart rates were not significantly different between the three groups, probably due to elimination of stimulatory effects from laryngeal mask airway and combitube. ${ }^{11,15}$ Generally, the greatest change in hemodynamic parameters was observed in diastolic blood pressure, which was higher at all stages after insertion in groups 2 as compared to the control group. In other words, application of laryngeal mask airway led to lower changes Several studies have shown that laryngeal mask airway insertion leads to far lower hemodynamic changes as compared to laryngoscopy and tracheal intubation. ${ }^{16,17}$ In terms of occurrence time, the maximum change in hemodynamic parameters was during the first minute after insertion, which exactly corresponded to maximum effect of stress responses induced by laryngoscopy and intubation. At 5 minutes after insertion, hemodynamic parameters in groups 1 attenuated to lower than even the baseline values, which was probably due to elimination of stimulatory effect and onset of drugs for maintenance of anesthesia. ${ }^{18}$ It should be noted that duration of inserting devices could also lead to intensified hemodynamic changes, because one of the most important measures taken to minimize such changes is shortening the duration of laryngoscopy and airway manipulation. ${ }^{19-21}$ The results of this study showed duration of combitube is much longer than that of laryngeal mask airway insertion. This is consistent with the findings of other studies ${ }^{13,17,22}$ and can partly explain the hemodynamic changes in patients applying combitube. This study revealed that the lowest hemodynamic changes during induction of anesthesia were observed in patients with simple mask ventilation (control group). Similarly, patients in laryngeal mask airway group experienced hemodynamic changes lower. Increased heart rates may cause a threat to the cardiovascular system by decreasing oxygen delivery to the myocardium and intensifying oxygen consumption as well as potential risks of hypertension in patients with cardiovascular diseases. According to this study, laryngeal mask airway insertion is highly recommended in patients undergoing elective surgery, particularly with ischemic heart disease and without risk of aspiration. However, we suggest that further studies to be carried out in this respect. We did not consider the pulse pressure parameters for hemodynamic evaluation. We also did not assess the variation of plasma catecholamine concentrations during our study. All of these concepts can be a subject for future studies, and we recommend that these can be done in larger study groups.

Anaesthesiology can be seen as a revolution when inventing supraglottic airway devices. They cause less sympathetic stimulation and prevent hemodynamic variability while they are inserted and developed. ${ }^{23}$ The risk of aspiration is also reduced by adding the most recent appliances with a separate gastric channel like laryngeal mask airway. In 050 they offer a good alternative to endotracheal intubation. The present study has shown that mean arterial pressure has increased during endotracheal intubation and baseline laryngeal mask airway insertion. ${ }^{22}$ The mean arterial pressure growth was significantly lower in laryngeal mask airway group when compared to the endotracheal tube group during insertion. Neither group of patients required more than two intubation or laryngeal mask airway insertions, so insertion/intubation failed. The results of the present study correlated with the study of Saraswat and coworkers. ${ }^{24}$ No other complication was reported in either group.

\section{CONCLUSION}

Intubation by intubating thelaryngeal mask airwayis accompanied by minimal cardiovascular response, as well as direct laryngoscopic tracheal intubation, which allows it to be used in patients who suffer from marked pressor response.

\section{REFERENCES}

1. Ismail SA, Bisher NA, Kandil HW, Mowafi HA, Atawia HA. Intraocular pressure and haemodynamic responses to insertion of the i-gel, laryngeal mask airway or endotracheal tube. Eur J Anaesthesiol 2011; 28: 443-8.

2. Atlee JL, Dhamee MS, Olund TL, George V. The use of esmolol, nicardipine, or their combination to blunt hemodynamic changes after laryngoscopy and tracheal intubation. Anesth Analg 2000; 90: 280-5.

3. Bhattacharya D, Ghosh S, Chaudhuri T, Saha S. Pressor responses following insertion of laryngeal mask airway in patients with controlled hypertension: comparison with tracheal intubation. J Indian Med Assoc 2008; 106: 787-810.

4. Kihara S, Brimacombe J, Yaguchi Y, Wantanbe S, Taguchi N, Komatsuzaki T. Hemodynamic responses among three tracheal intubation devices in normotensive and hypertensive patients. Anesth Analg 2003; 96: 890-5.

5. Yoo K, Joeng $\mathrm{S}, \mathrm{Ha} \mathrm{H}$, Lee J. Nitrous oxide attenuates pressor but augments norepinephrine response to laryngoscopy and endotracheal intubation. Anesth Analg. 2003; 96: 1516-21. 
6. Khoury SI, Dabbous AS, Rizk LB, Aboujalad NM, Bartelmoas TE, Elkhatib MF et al. A combination of alfentanil-lidocainepropofol provides better intubating condition than fentanyllidocaine-propofol in the absence of muscle relaxant. Can $\mathrm{J}$ Anesth 2003; 50: 116-20.

7. Habib AS, Parker JL, Maguire AM, Rowbothan DJ, Thompsan JP. Effects of remifentanil and alfentanil on the cardiovascular response to induction of anesthesia and tracheal intubation in elderly. Br J Anesth 2002; 88: 430-3.

8. Singh SP, Quadir A, Malhotra P. Comparison of esmolol and labetalol, in low doses, for attenuation of sympathomimetic response to laryngoscopy and intubation. Saudi J Anaesth 2010; 4: 163-8.

9. MarashiSm, Ghafari MH, Saliminia A. Attenuation of hemodynamic responses following laryngoscopy and tracheal intubation - comparative assessment of clonidine and gabapentin premedication. Middle East J Anesthesiol 2009; 20: 233-7.

10. Sharma VS, Tidke S, Premendran BJ. A comparative study of overall efficacy and hemodynamic effects following blind orotracheal intubation with ILMA vs. conventional direct laryngoscopy guided intubation with Macintosh laryngoscope. Int J Clin Trials 2014; 1(2):31-6.

11. Tabari M, Alipour M, Ahmadi M. Hemodynamic changes occurring with tracheal intubation by direct laryngoscopy compared with intubating laryngeal mask airway in adults: a randomized comparison trial. Egypt $\mathrm{J}$ Anaesthesia 2013;29(2):103-7.

12. Ocker H, Wenzel V, Schmucker $P$, Steinfath $M$, Dörges V. A comparison of the laryngeal tube with the laryngeal mask airway during hemodynamic responses to insertion of the LMA versus routine surgical procedures. Anesthesia Analgesia 2002;95(4):1094-7.

13. Sheinbaum R. Combitube: esophageal/tracheal-double lumen airway. In: Gegberg C, ed, Benumof and Hagberg's airway management. $3^{\text {rd }}$ ed. Philadelphia: WB Saunders, 2013; 57090.
14. Takita K, Morimoto $\mathrm{Y}$, Kemmotsa O. Tracheal lidocaine attenuate the cardiovascular response to endotracheal intubation. Can J Anesth 2001; 48:732-6.

15. Cook T, McCormick B, Asai T. Randomized comparison of laryngeal tube with classic laryngeal mask airway for anaesthesia with controlled ventilation. $\mathrm{Br} \mathrm{J}$ Anaesthesia 2003;91(3):373-8.

16. Wilson JG, Fell D, Robinson SL, Smith G. Cardiovascular responses to insertion of laryngeal mask airway. Anaesthesia 1992; 47: 300.

17. Ashraf N, Akhgar F. Hemodynamic responses to laryngoscopy and intubation: propofol versus thiopental sodium. Tehran Univ Med J 2008;66(1):18-24.

18. Kumar S, Mishra MN, Mishra LS. Comparative study of the efficacy of IV Esmolol, diltiazem and magnesium sulphate in hemodynamic response to laryngoscopy and tracheal intubation. Indian J Anaesth 2003; 47:41-4.

19. Brain A, Denman W, Goudsouzian N. Laryngeal mask airway instruction manual. San Diego, Calif: LMA North America Inc. 1999.

20. Sood J. Laryngeal mask airway and its variants. Indian J Anaesth 2005; 49(4):275-80.

21. Fujii $\mathrm{Y}$, Tanaka H, Toyooka $H$. Circulatory responses to laryngeal mask airway insertion or tracheal intubation in normotensive and hypertensive patients. Canadian $\mathrm{J}$ Anaesthesia 1995;42(1):32-6.

22. Arshad Z, Abbas H, Bogra J, Saxena S. Comparison of laryngoscopic view and hemodynamic changes with flexitip McCoy and Macintosh laryngoscope blade in predicted easy and difficult airway. 2013;3(5).

23. Mehta KH, Sharma SA, Pandav VB. A comparison of proseal LMA and endotracheal intubation in laparoscopic tubal ligation. Int J Anaesthesiol 2013; 4: 2277-9.

24. Saraswat N, Kumar A, Mishra A, Gupta A, Saurabh G, Srivastava U. The comparison of Proseal laryngeal mask airway and endotracheal tube in patients undergoing laparoscopic surgeries under general anaesthesia. Indian $\mathrm{J}$ Anaesth 2011; 55: 129-34. 